\title{
MICROSTRUCTURE AND MECHANICAL PROPERTIES OF ULTRAFINE WC/Co CEMENTED CARBIDES WITH CUBIC BORON NITRIDE AND $\mathrm{Cr}_{3} \mathrm{C}_{2}$ ADDITIONS
}

\author{
GENRONG ZHANG*, "HAIYAN CHEN**, LIHUA DONG**, YANSHENG YIN**, KUN LI** \\ *Logistics Engineering College, Shanghai Maritime University, Shanghai 201306, China \\ **College of Ocean Science and Engineering, Shanghai Maritime University, Shanghai 201306, China \\ \#E-mail: hychen@shmtu.edu.cn
}

Submitted September 23, 2015; accepted January 28, 2016

\begin{abstract}
Keywords: Crystal inhibitor, Mechanical properties, Ultrafine microstructure, Cemented carbide, Tungsten carbide, Chromium carbide, Cubic boron nitride

This study investigates the microstructure and mechanical properties of ultrafine tungsten carbide and cobalt (WC/Co) cemented carbides with cubic boron nitride $(\mathrm{CBN})$ and chromium carbide $\left(\mathrm{Cr}_{3} \mathrm{C}_{2}\right)$ fabricated by a hot pressing sintering process. This study uses samples with $8 \mathrm{wt} . \% \mathrm{Co}$ content and $7.5 \mathrm{vol} . \% \mathrm{CBN}$ content, and with different $\mathrm{Cr}_{3} \mathrm{C}_{2}$ content ranging from 0 to $0.30 \mathrm{wt}$. \%. Based on the experimental results, $\mathrm{Cr}_{3} \mathrm{C}_{2}$ content has a significant influence on inhibiting abnormal grain growth and decreasing grain size in cemented carbides. Near-full densification is possible when $C B N-W C / C o$ with $0.25 \mathrm{wt} . \% \mathrm{Cr}_{3} \mathrm{C}_{2}$ is sintered at $1350^{\circ} \mathrm{C}$ and $20 \mathrm{MPa}$; the resulting material possesses optimal mechanical properties and density, with an acceptable Vickers hardness of $19.20 \mathrm{GPa}$, fracture toughness of $8.47 \mathrm{MPa} \cdot \mathrm{m}^{1 / 2}$ and flexural strength of $564 \mathrm{MPa}$.
\end{abstract}

\section{INTRODUCTION}

Research has provided sufficient evidence that the hardness, strength, and overall performance of cemented carbides are greatly enhanced when the grain size is ultrafine. Because the grain size seriously affects the performance of cemented carbides, a great deal of research has examined how to inhibit normal grain growth and prevent abnormal grain growth [1-4].

Tungsten carbide and cobalt $(\mathrm{WC} / \mathrm{Co})$ cemented carbides are materials with a unique combination of hardness, wear-resistance, toughness and strength that makes them appropriate candidates for numerous applications [5]. In fact, cubic boron nitride (CBN) is the second hardest material on Earth, being considerably harder than tungsten carbide. Therefore, the addition of dispersed ultrafine $\mathrm{CBN}$ particles is expected to increase the hardness of $\mathrm{WC} / \mathrm{Co}$ cemented carbide. However, based on developments over the last few decades, finer tungsten carbide (WC) might be manufactured to achieve better mechanical properties such as strength and toughness in CBN-WC/Co cemented carbide [6-8]. However, ultrafine WC powder demonstrates high activity in the sintering densification process, and thus ultrafine $\mathrm{WC}$ particles are prone to reunion and grain coalescence phenomena. Therefore, it is difficult to achieve high relative density and other useful properties in binderless ultrafine cemented carbides, making the inhibition of abnormal growth in $\mathrm{WC}$ grains a significant problem in its application. In order to inhibit grain growth in $\mathrm{CBN}-\mathrm{WC} / \mathrm{Co}$, this study uses $\mathrm{Cr}_{3} \mathrm{C}_{2}$ to prevent excessive growth in $\mathrm{WC}$ particles. As a common grain growth inhibitor, $\mathrm{Cr}_{3} \mathrm{C}_{2}$ not only has high solubility in Co solutions but also has a low eutectic temperature in Co systems. Therefore, $\mathrm{Cr}_{3} \mathrm{C}_{2}$ is particularly appropriate as a grain growth inhibitor in CBN-WC/Co cemented carbide [9-12].

In recent years, some internationally famous cemented carbide production enterprises, such as the Sandvik Group in Sweden, Kennametal, Inc., in the United States, and Mitsubishi Materials Corporation and Toshiba Corporation in Japan, have produced cemented carbide with a $200 \mathrm{~nm}$ grain size for industrial-scale preparation. In addition, researchers such as Bonache et al. have investigated the effects of grain inhibition on the microstructure and mechanical properties of $\mathrm{VC} / \mathrm{Cr}_{3} \mathrm{C}_{2}$-containing $\mathrm{WC} / \mathrm{Co}$ prepared by a plasma sintering process [13]. According to previous research, cemented carbides have better mechanical properties when the $\mathrm{Cr}_{2} \mathrm{C}_{3}$ content is less than $3 \%$. However, although research has investigated the influence of the $\mathrm{Cr}_{3} \mathrm{C}_{2}$ content in a wide range from 0 to $0.9 \%$, no specialized studies have investigated $\mathrm{Cr}_{3} \mathrm{C}_{2}$ content in the range from 0 to $0.3 \%$. In addition, very few references discuss the effect of $\mathrm{Cr}_{3} \mathrm{C}_{2}$ when added to the $\mathrm{CBN}-\mathrm{WC} /$ Co system. 
In this study, cemented carbides based on ultrafine WC/Co with various amounts of added $\mathrm{Cr}_{3} \mathrm{C}_{2}$ inhibitors were fabricated using a hot pressing sintering process. This work explores the effects of the added amounts of inhibitor on density, microstructure, fracture toughness and hardness, as compared with a control specimen without added inhibitors.

\section{EXPERIMENTAL}

Prior to the experiment, the Co content was determined to be 8 wt. \%; the content of CBN was 7.5 vol. \%. These measurements were performed in order to guarantee that the experimental material had optimal mechanical and sintering properties, i.e. a composition appropriate for achieving sufficient mechanical properties while avoiding a decrease of sinterability of the powders [7].

Table 1 lists the main characteristics of the WC, Co, $\mathrm{CBN}$ and $\mathrm{Cr}_{3} \mathrm{C}_{2}$ starting powders. Table 2 describes the composition of each specimen and the nomenclature used in this paper. In the experiment, the $\mathrm{CBN}-\mathrm{WC} / \mathrm{Co}$ composite powders were prepared using a high-energy ball milling method in which the milling ball was carbide and the milling medium was ethanol. Additionally, a graphite mold was used in the hot pressing sintering process. First, different amounts of raw $\mathrm{Cr}_{3} \mathrm{C}_{2}$ powder were weighed by electronic balance, with results shown in Table 2. Then the powders were placed in a ball milling tank, and ethanol was added to the tank to serve as the ball milling medium. The ball milling tank was placed into the ball mill at a milling speed of $400 \mathrm{rpm}$ (rotations per minute) for 48 hours. Finally, when the milling was completed, the powder mixture was placed in a drying oven for two hours at $70^{\circ} \mathrm{C}$, after which the dried powder was sieved twice, using a 100 mesh (149 microns) sieve.

Next, the sieved powder was poured into a graphite mold (diameter $50 \mathrm{~mm}$, height $100 \mathrm{~mm}$ ) and placed in a hot press sintering furnace. The sintering process was

Table 1. Powders used in the experiment (producers' data).

\begin{tabular}{lccl}
\hline Powder & $\mathrm{D}_{50}(\mu \mathrm{m})$ & Purity $(\%)$ & Supplier \\
\hline WC & 2.41 & 99.99 & Jinlu Tungsten Co. Ltd., China \\
$\mathrm{Co}$ & 0.8 & 99.9 & Nanjing Hanrui Co. Ltd., China \\
$\mathrm{CBN}$ & 1.5 & 99.9 & Jiete Co. Ltd., China \\
$\mathrm{Cr}_{3} \mathrm{C}_{2}$ & 1.35 & 99.7 & Jiujiang Bode Co. Ltd., China \\
\hline
\end{tabular}

performed in a resistance-heated furnace at temperatures between $1300^{\circ} \mathrm{C}$ and $1400^{\circ} \mathrm{C}$. The powder was sintered under a pressure of $20 \mathrm{MPa}$ for 90 minutes in a vacuum environment.

The density of each specimen was measured by immersion in water using the Archimedes principle, so that the relative density of cemented carbides with different $\mathrm{Cr}_{3} \mathrm{C}_{2}$ contents could be calculated. The microstructures were observed and analyzed with a scanning electron microscope (FE-SEM). Phase analysis was performed with an X-ray diffractometer (XRD) at $2 \theta$ (2 theta) angles ranging from $20^{\circ}$ to $80^{\circ}$. Hardness and fracture toughness were measured using the Vickers hardness and fracture toughness tester or Vickers indenter under a constant load of $5 \mathrm{~kg}$. Finally, the samples were cut into segments of dimensions $3 \times 4 \times 30 \mathrm{~mm}$, which were directly placed on a microcomputer-controlled electronic testing machine without any treatment for the three-point bending strength test.

For accuracy, the specimens were polished to a near-mirror finish and checked for face parallelism before testing. All mechanical properties tests were conducted three times and the arithmetic mean value of the three test results was taken to be the final result.

\section{RESULTS AND DISCUSSION}

\section{Microstructure and X-ray diffraction analysis}

Figure 1 shows the SEM images of the cemented carbides containing $0,0.15,0.20,0.25$ and 0.30 wt. $\%$ of $\mathrm{Cr}_{3} \mathrm{C}_{2}$, sintered at $1350^{\circ} \mathrm{C}$ under $20 \mathrm{MPa}$ pressure. Figure 1a shows abnormal growth of grains in the fracture surface of the specimen without any grain growth inhibitor. As the content of $\mathrm{Cr}_{3} \mathrm{C}_{2}$ increases, the $\mathrm{CBN}$ $\mathrm{WC} / \mathrm{Co}$ cemented carbide grain microstructure becomes more uniform and compact; however, when the content exceeds 0.25 wt. $\%$, the grain size variation decreases, and no change is apparent between the final two specimens, $2.5 \mathrm{Cr}_{3} \mathrm{C}_{2}$ and $3.0 \mathrm{Cr}_{3} \mathrm{C}_{2}$.

The SEM images of each specimen serve as evidence of the effect of $\mathrm{Cr}_{3} \mathrm{C}_{2}$ in inhibiting abnormal grain growth. This effect may be attributed to a combination of several factors: (1) WC grain growth occurs by Ostwald ripening, with smaller WC grains dissolving and

Table 2. Composition and nomenclature of powder blends.

\begin{tabular}{lcccccc}
\hline $\begin{array}{l}\text { Specimen } \\
\text { name }\end{array}$ & $\begin{array}{c}\text { WCCo } \\
\text { (wt. \%) }\end{array}$ & $\begin{array}{c}\mathrm{Cr}_{3} \mathrm{C}_{2} \\
(\text { wt. \%) }\end{array}$ & (wt. \%) & (vol. \%) & (wt. \%) & $\begin{array}{c}\text { Theoretical density } \\
\left(\mathrm{g} \cdot \mathrm{cm}^{-3}\right)\end{array}$ \\
\hline $0 \mathrm{Cr}_{3} \mathrm{C}_{2}$ & 90.12 & 8 & 0.00 & 7.5 & 1.88 & 14.8632 \\
$1.5 \mathrm{Cr}_{3} \mathrm{C}_{2}$ & 89.97 & 8 & 0.15 & 7.5 & 1.88 & 14.8498 \\
$2.0 \mathrm{Cr}_{3} \mathrm{C}_{2}$ & 89.91 & 8 & 0.20 & 7.5 & 1.89 & 14.8441 \\
$2.5 \mathrm{Cr}_{3} \mathrm{C}_{2}$ & 89.86 & 8 & 0.25 & 7.5 & 1.89 & 14.8396 \\
$3.0 \mathrm{Cr}_{3} \mathrm{C}_{2}$ & 89.81 & 8 & 0.30 & 7.5 & 1.89 & 14.8351 \\
\hline
\end{tabular}


re-precipitating on larger grains in the Co binder phase. The dispersal of the inhibitor $\mathrm{Cr}_{3} \mathrm{C}_{2}$ in the ultrafine $\mathrm{WC}$ powder reduces the surface energy of the solid $\mathrm{WC}$ particles, resulting in a change in the force driving small grains to dissolve and large grains to grow. The change of surface energy inhibits the continued growth of WC

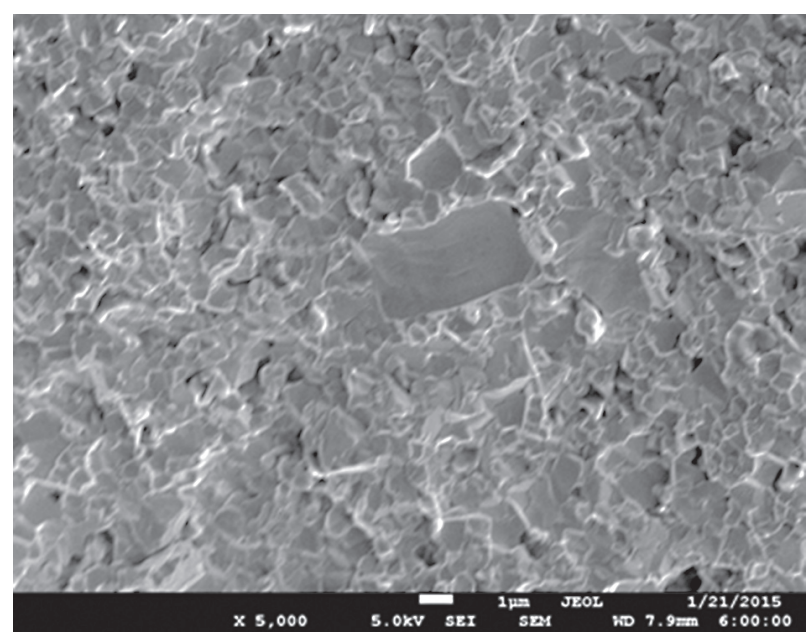

a) $0 \mathrm{Cr}_{3} \mathrm{C}_{2}$

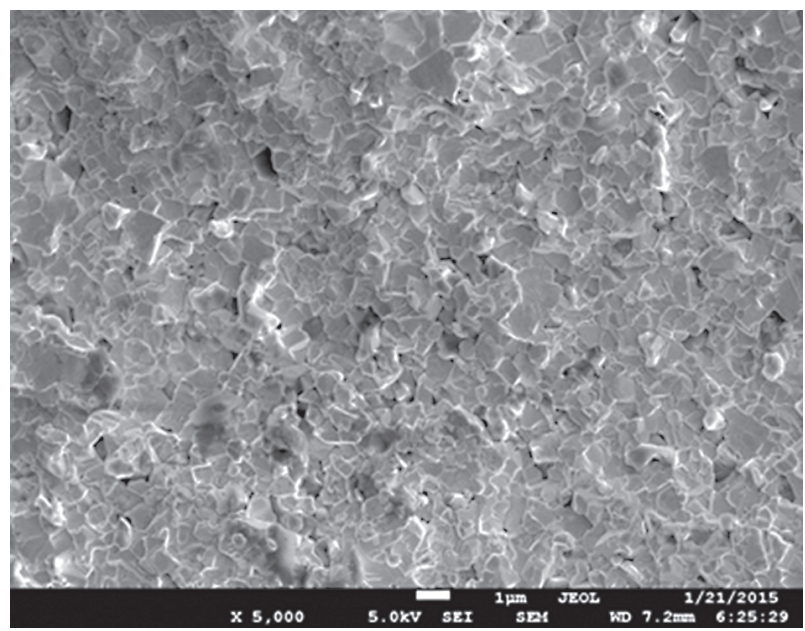

b) $1.5 \mathrm{Cr}_{3} \mathrm{C}_{2}$

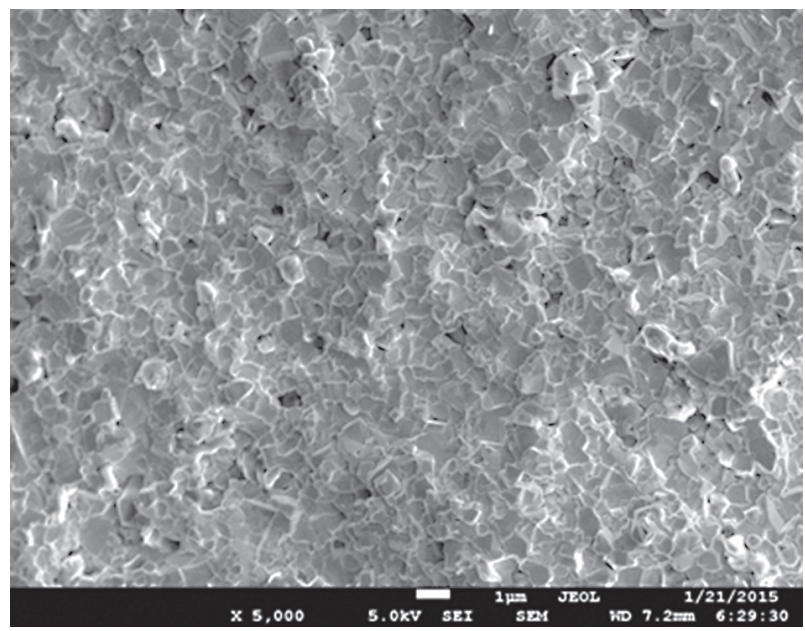

c) $2.0 \mathrm{Cr}_{3} \mathrm{C}_{2}$ grains. (2) The inhibitor can form steady radicals in the binder Co, such as $\mathrm{W}$ and $\mathrm{CrC}$. These can prevent $\mathrm{W}$ and $\mathrm{C}$ atoms transferring from one grain to another, which limits the grain growth of WC [11]. (3) The inhibitor can prevent the phase migration that increases the amount of single WC grains by preventing the agglomeration and coalescence of WC.

However, when the content of $\mathrm{Cr}_{3} \mathrm{C}_{2}$ exceeded 0.25 wt. $\%$, no abnormal grain growth is present in the $\mathrm{CBN}-\mathrm{WC} / \mathrm{Co}$ system any more. Therefore, the further addition of $\mathrm{Cr}_{3} \mathrm{C}_{2}$ content to the system will not lead to further improvement of the performance of the cemented carbides.

$\mathrm{X}$-ray diffraction of the original $\mathrm{WC}, \mathrm{Co}$ and $\mathrm{CBN}$ powders was carried out before the hot pressing, with results shown in Figure 2. Figure 3 displays the X-ray diffraction patterns of the cemented carbides with different $\mathrm{Cr}_{3} \mathrm{C}_{2}$ contents. The figure clearly shows the peaks corresponding to $\mathrm{WC}$, but peaks corresponding to $\mathrm{CBN}, \mathrm{Cr}_{3} \mathrm{C}_{2}$ and even Co could not be identified, obviously because in the composite the content of these phases is so low that it is below the XRD detection limit.

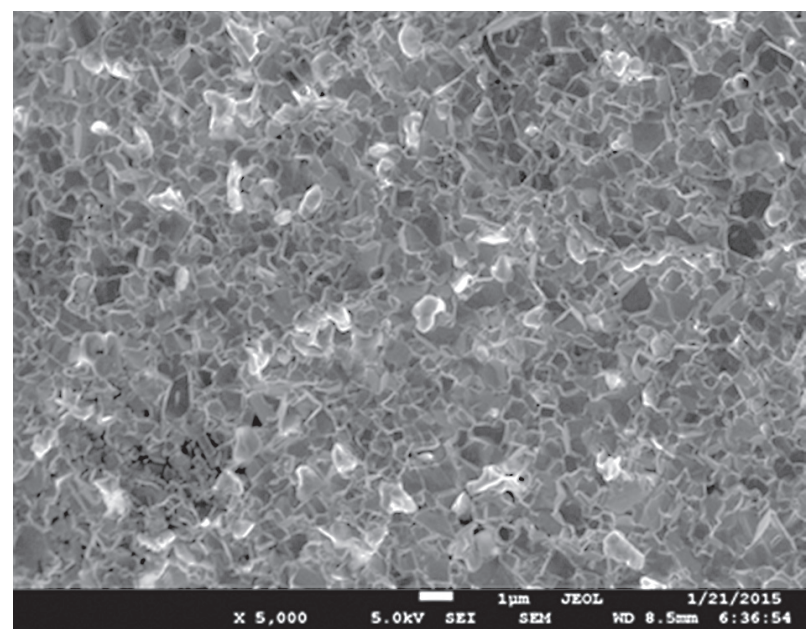

d) $2.5 \mathrm{Cr}_{3} \mathrm{C}_{2}$

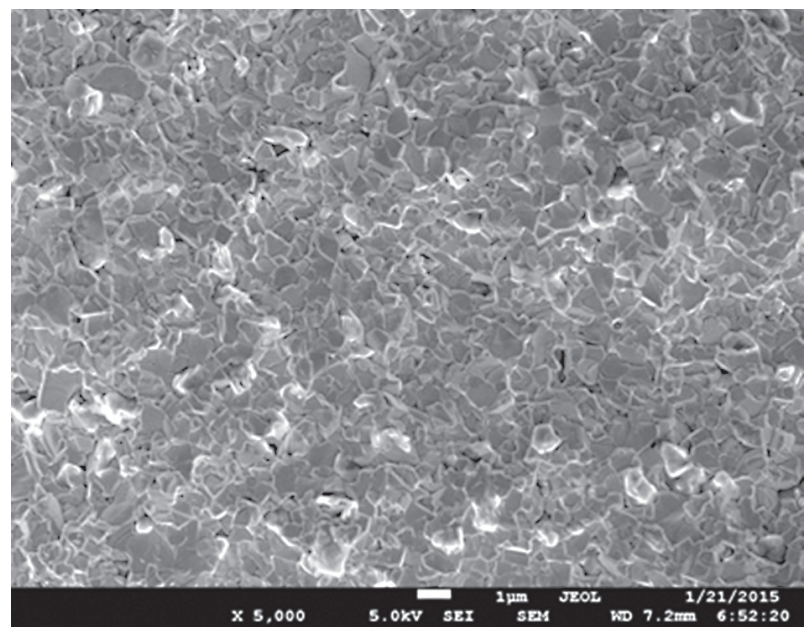

e) $3.0 \mathrm{Cr}_{3} \mathrm{C}_{2}$

Figure 1. Microstructure of: a) $0 \mathrm{Cr}_{3} \mathrm{C}_{2}$, b) $1.5 \mathrm{Cr}_{3} \mathrm{C}_{2}$, c) $2.0 \mathrm{Cr}_{3} \mathrm{C}_{2}$, d) $2.5 \mathrm{Cr}_{3} \mathrm{C}_{2}$, and e) $3.0 \mathrm{Cr}_{3} \mathrm{C}_{2}$ after hot pressing at $1350^{\circ} \mathrm{C}$ and $20 \mathrm{MPa}$. 


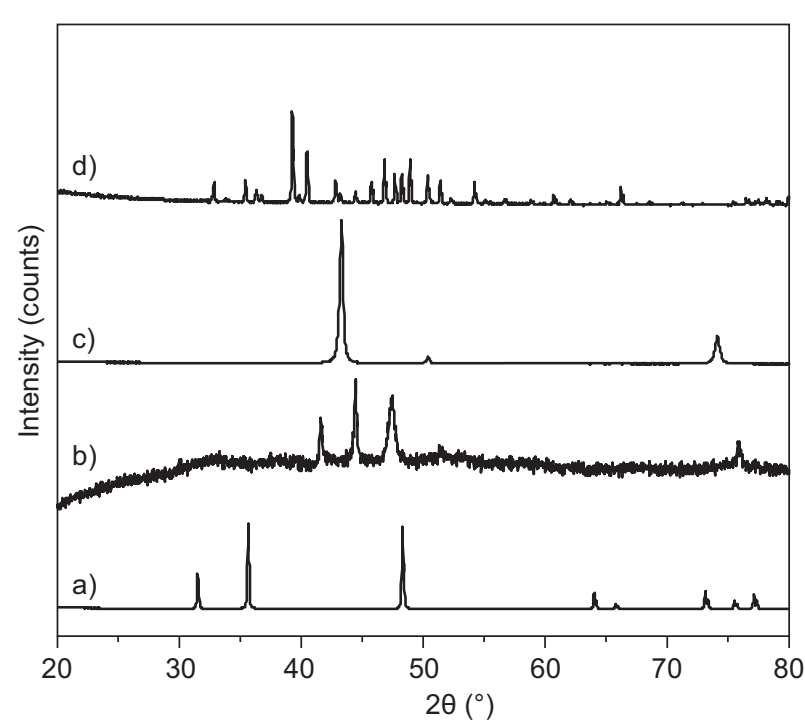

Figure 2. X-ray diffraction analysis of: a) $\mathrm{WC}, \mathrm{b}$ ) $\mathrm{Co}$, c) $\mathrm{CBN}$, and d) $\mathrm{Cr}_{3} \mathrm{C}_{2}$.

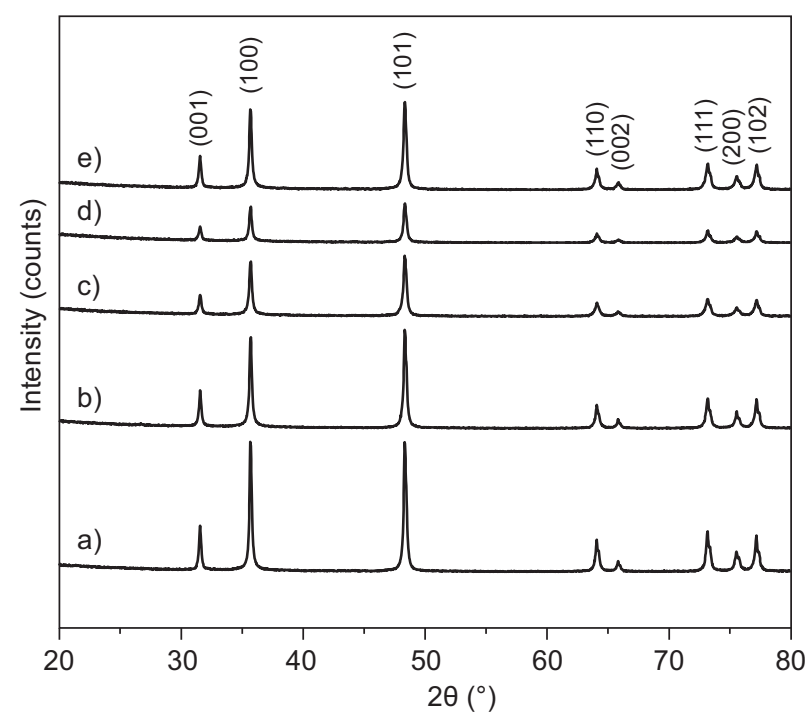

Figure 3. X-ray diffraction patterns of cemented carbides (WC) with $\mathrm{Cr}_{3} \mathrm{C}_{2}$ content of: a) 0 wt. $\%$, b) 0.15 wt. \%, c) 0.20 wt. $\%$, d) 0.25 wt. $\%$, and e) 0.30 wt. $\%$.

\section{Density and open porosity}

Figure 4 shows the bulk density and open porosity of the $\mathrm{CBN}-\mathrm{WC} / \mathrm{Co}$ cemented carbides prepared with different $\mathrm{Cr}_{3} \mathrm{C}_{2}$ contents, as calculated using the Archimedes principle. According to the experimental results, as the content of $\mathrm{Cr}_{3} \mathrm{C}_{2}$ increases, density decreases slightly and also the open porosity decreases as the $\mathrm{Cr}_{3} \mathrm{C}_{2}$ content increases from 0 to $0.25 \mathrm{wt}$. \%. Notably, however, the open porosity increases again when the $\mathrm{Cr}_{3} \mathrm{C}_{2}$ content rises to $0.30 \mathrm{wt}$. \%, which may adversely affect some mechanical properties on the local scale, e.g. Vickers hardness (see below). Nevertheless, the absolute values of open porosity are very small $(0.2-0.9 \%)$, so that dramatic effects on the mechanical properties cannot be expected. Although the theoretical density of $\mathrm{Cr}_{3} \mathrm{C}_{2}\left(6.68 \mathrm{~g} \cdot \mathrm{cm}^{-3}\right)$ is much smaller than the theoretical density of WC $\left(15.63 \mathrm{~g} \cdot \mathrm{cm}^{-3}\right)$, the content of $\mathrm{Cr}_{3} \mathrm{C}_{2}$ is very low and it is completely dissolved in liquid Co during the sintering process, so the theoretical density of the cemented carbides will hardly be affected by the content of $\mathrm{Cr}_{3} \mathrm{C}_{2}$. Of course, the slight decrease of the bulk density is expected to be connected with a slight increase of the total porosity. However, both bulk density and total porosity exhibit only a very slight dependence on the $\mathrm{Cr}_{3} \mathrm{C}_{2}$ content. Since the bulk density is almost constant, the influence of total porosity on the mechanical properties can be expected to be almost negligible in the present work.

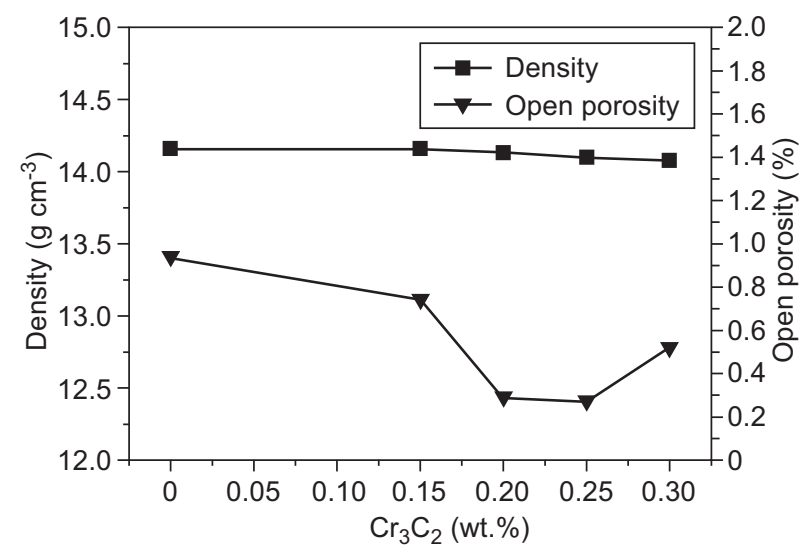

Figure 4. Dependence of density and open porosity on $\mathrm{Cr}_{3} \mathrm{C}_{2}$ content.

\section{Mechanical properties}

Hardness and fracture toughness are the two most important mechanical properties of cemented carbides. As Figure 5 shows, as the $\mathrm{Cr}_{3} \mathrm{C}_{2}$ content ranges from 0 to $0.25 \mathrm{wt}$ \%, both the Vickers hardness and fracture toughness of the $\mathrm{CBN}-\mathrm{WC} / \mathrm{Co}$ cemented carbides improve significantly. Over this range of $\mathrm{Cr}_{3} \mathrm{C}_{2}$ content,

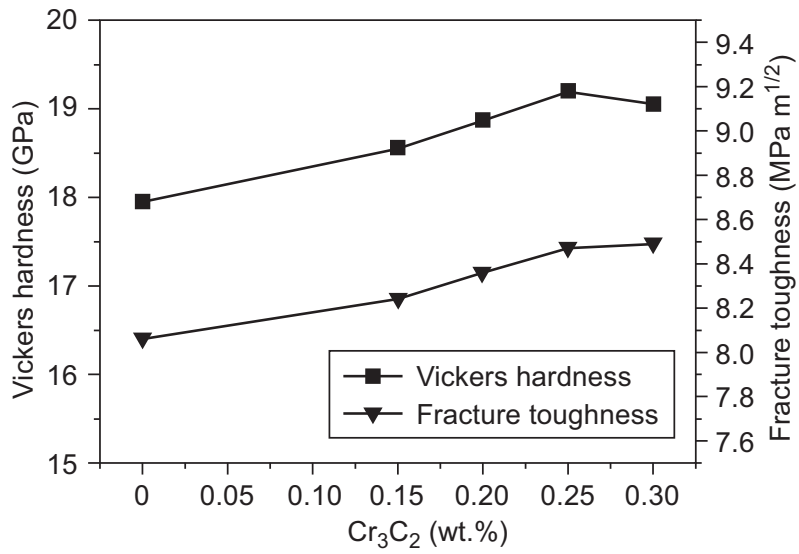

Figure 5. Dependence of hardness and fracture toughness on $\mathrm{Cr}_{3} \mathrm{C}_{2}$ content. 
the Vickers hardness increases from $17.95 \mathrm{GPa}$ to 19.20 GPa, and the fracture toughness increases from 8.06 $\mathrm{MPa}$ to $8.47 \mathrm{MPa}$. When the $\mathrm{Cr}_{3} \mathrm{C}_{2}$ content is increased from 0.25 to $0.30 \mathrm{wt} \%$, the fracture toughness remains almost constant, and the Vickers hardness even decreases slightly, from 19.20 GPa to $19.05 \mathrm{GPa}$, possibly because of the aforementioned slight increase in open porosity.

The Vickers hardness of the sintered cemented carbide grows as the $\mathrm{Cr}_{3} \mathrm{C}_{2}$ content increases. This occurs because with the addition of $\mathrm{Cr}_{3} \mathrm{C}_{2}$, the grain size of the cemented carbides becomes finer. The fine grain strengthening theory states that the finer the grain size, the more grain boundaries can be found on a piece of material of the same size, and the atoms arrange irregularly on grain boundaries with more impurities and defects and higher energy. Hence, greater obstacles to dislocation motion and greater resistance to deformation arise, and Vickers hardness improves as a result. When the $\mathrm{Cr}_{3} \mathrm{C}_{2}$ content exceeds 0.25 wt. \%, the increase of the hardness values decrease again. Apart from the aforementioned slight increase of open porosity due to excess $\mathrm{Cr}_{3} \mathrm{C}_{2}$ this may be because the excessive addition of the inhibitor has a decreased inhibition effect on grain growth, such that the improvement in hardness of the cemented carbides is reduced. In addition, the fracture toughness of WC-Co in cemented carbides is affected by the grain size of WC and the content of the Co binding phase. This study fixed the content of Co binding phase, so the reasons behind the fracture toughness increase here can be attributed only to the influence of the WC grain size. First, according to the fine grain strengthening theory, the finer the grain size, the more grains are present in a given volume, which means the same plastic deformation is scattered in more grains. Therefore, less dislocations are produced in each grain, and the stress concentration caused by cracking also decreases. Second, the larger the grain boundary area, the more twists and turns the grain boundary has, which are not conducive to the expansion of cracks. Furthermore, the addition of $\mathrm{Cr}_{3} \mathrm{C}_{2}$ can significantly inhibit the formation of $\mathrm{Co}_{6} \mathrm{~W}_{6} \mathrm{C}$, which is a hard and brittle compound compared with decreased fracture toughness. Therefore, the fracture toughness may improve through the combined influence of these three aspects.

Figure 6 shows the variations in flexural strength in dependence of the $\mathrm{Cr}_{3} \mathrm{C}_{2}$ content in $\mathrm{CBN}-\mathrm{WC} / \mathrm{Co}$ cemented carbides. When the $\mathrm{Cr}_{3} \mathrm{C}_{2}$ content ranges from 0 to 0.15 wt. $\%$, the flexural strength improves slightly. When the content of $\mathrm{Cr}_{3} \mathrm{C}_{2}$ reaches $0.20 \mathrm{wt}$. \%, the flexural strength increases significantly. However, when the $\mathrm{Cr}_{3} \mathrm{C}_{2}$ content exceeds 0.20 wt. \%, the increase in flexural strength is very limited.

Flexural strength clearly increases with the increase of $\mathrm{Cr}_{3} \mathrm{C}_{2}$ content. This can be explained from two perspectives. On the one hand, with the prevention of abnormal WC grain growth, contact between WC grains decreases and Co distribution becomes more uniform, improving both the deformation path of $\mathrm{Co}$ and the effective range of the deformation, which in turn improves the bending strength. On the other hand, as the WC grain size becomes smaller, the grain uniformity improves. When the grains become refined and the WC content remains constant, the increase in grain number can also lead to an increase in the deformation path of Co. Therefore, the improvement of WC particle size uniformity and the increase of available deformation paths of Co mean that higher contents of $\mathrm{Cr}_{3} \mathrm{C}_{2}$ correspond with higher bending strength. However, when the $\mathrm{Cr}_{3} \mathrm{C}_{2}$ content exceeds 0.20 wt. $\%$, the size and uniformity of the grain increase only slightly, and therefore the bending strength of the material also only marginally increases.

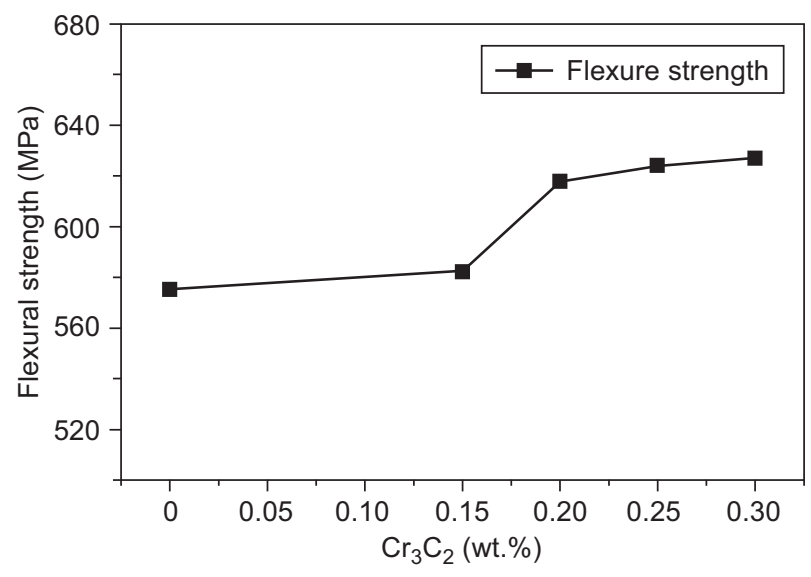

Figure 6. Dependence of flexural strength on $\mathrm{Cr}_{3} \mathrm{C}_{2}$ content.

\section{CONCLUSIONS}

The addition of $\mathrm{Cr}_{3} \mathrm{C}_{2}$ to cemented carbide improves Vickers hardness, fracture toughness and flexural strength, and it plays a significant role in inhibiting abnormal grain growth and decreasing grain size. The influences of the $\mathrm{Cr}_{3} \mathrm{C}_{2}$ addition on mechanical properties are consistent with the effects of grain growth inhibition. When the mass fraction of $\mathrm{Cr}_{3} \mathrm{C}_{2}$ remains less than 0.25 wt. $\%$, increasing contents of the grain growth inhibitor have a more obvious inhibitory effect, including a significant improvement of hardness, fracture toughness and flexural strength of the cemented carbides. However, when the content of $\mathrm{Cr}_{3} \mathrm{C}_{2}$ exceeds 0.25 wt. \%, the additional inhibitory effect is less obvious, i.e. the grain size cannot be reduced significantly by adding further $\mathrm{Cr}_{3} \mathrm{C}_{2}$.

A $\mathrm{Cr}_{3} \mathrm{C}_{2}$ content of 0.25 wt. $\%$ allows near-full densification at $1350^{\circ} \mathrm{C}$ and $20 \mathrm{MPa}$ via hot pressing sintering; it reaches an optimal hardness of $19.20 \mathrm{GPa}$, fracture toughness of $8.47 \mathrm{MPa} \cdot \mathrm{m}^{1 / 2}$ and flexural strength of $564 \mathrm{MPa}$, and therefore optimal overall mechanical performance. We can conclude that $\mathrm{Cr}_{3} \mathrm{C}_{2}$ is an effective sintering aid in inhibiting grain growth and improving mechanical properties. 
Acknowledgments

This work was supported by research funds projects of State Oceanic Administration People's Republic of China (201405013-3)

\section{REFERENCES}

1. Nino A., Takahashi N., Sugiyama S., Takamatsu H. (2014): Effects of carbide grain growth inhibitors on the microstructures and mechanical properties of $\mathrm{WC}-\mathrm{SiC}-\mathrm{Mo}$ $2 \mathrm{C}$ hard ceramics. International Journal of Refractory Metals and Hard Materials, 43, 150-156. doi:10.1016/j. ijrmhm.2013.11.016

2. Lee K. H., Cha S. I., Kim B. K., Hong S. H. (2006): Effect of $\mathrm{WC} / \mathrm{TiC}$ grain size ratio on microstructure and mechanical properties of $\mathrm{WC}-\mathrm{TiC}-\mathrm{Co}$ cemented carbides. International Journal of Refractory Metals and Hard Materials, 24, 109-114. doi:10.1016/j.ijrmhm.2005.04.018

3. Han S. Z., Goto M., Ahn J., Lim S. H., Kim S., Lee J. (2014): Grain growth in ultrafine grain sized copper during cyclic deformation. Journal of Alloys and Compounds, 615, S587-S589. doi:10.1016/j.jallcom.2013.12.004

4. Adorjan A., Schubert W. D., Bock A., Zeiler B. (2006): WC grain growth during the early stages of sintering. International Journal of Refractory Metals and Hard Materials, 24, 365-373. doi: 10.1016/j.ijrmhm.2005.11.009

5. Shi X. L., Shao G. Q., Duan X. L., Xiong Z., Yang H. (2006): Characterizations of $\mathrm{WC}-10 \mathrm{Co}$ nanocomposite powders and subsequently sinterhip sintered cemented carbide. Materials characterization, 57(4), 358-370. doi:10.1016/j. matchar.2006.02.013

6. Zhao Y., Wang M. (2009): Effect of sintering temperature on the structure and properties of polycrystalline cubic boron nitride prepared by SPS. Journal of materials processing technology, 209(1), 355-359. doi:10.1016/j. jmatprotec.2008.02.005

7. Yaman B., Mandal H. (2014): Wear performance of spark plasma sintered $\mathrm{Co} / \mathrm{WC}$ and $\mathrm{cBN} / \mathrm{Co} / \mathrm{WC}$ composites. International Journal of Refractory Metals and Hard Materials, 42, 9-16. doi:10.1016/j.ijrmhm.2013.10.010

8. Wang B., Qin Y., Jin F., Yang J. F., Ishizaki K. (2014): Pulse electric current sintering of cubic boron nitride/tungsten carbide-cobalt (cBN/WC-Co) composites: Effect of cBN particle size and volume fraction on their microstructure and properties. Materials Science and Engineering: A, 607, 490-497. doi:10.1016/j.msea.2014.04.029

9. Espinosa L., Bonache V., Salvador M. D. (2011): Friction and wear behaviour of $\mathrm{WC}-\mathrm{Co}-\mathrm{Cr} 3 \mathrm{C} 2-\mathrm{VC}$ cemented carbides obtained from nanocrystalline mixtures. Wear, 272(1), 62-68. doi:10.1016/j.wear.2011.07.012

10. Lee W. B., Kwon B. D., Jung S. B. (2006): Effects of $\mathrm{Cr}_{3} \mathrm{C}_{2}$ on the microstructure and mechanical properties of the brazed joints between WC-Co and carbon steel. International Journal of Refractory Metals and Hard Materials, 24, 215-221. doi:10.1016/j.ijrmhm.2005.04.003

11. Jia C., Xiong J. (2011): VC, $\mathrm{Cr}_{3} \mathrm{C}_{2}$ doped ultrafine WCCo cemented carbides prepared by spark plasma sintering. International Journal of Refractory Metals and Hard Materials, 29, 147-152. doi:10.1016/j.ijrmhm.2010.09.004

12. Sun L., Jia C., Cao R., Lin C. (2008): Effects of $\mathrm{Cr}_{3} \mathrm{C}_{2}$ additions on the densification, grain growth and properties of ultrafine $\mathrm{WC}-11 \mathrm{Co}$ composites by spark plasma sintering. International Journal of Refractory Metals and Hard Materials, 26, 357-361. doi:10.1016/j.ijrmhm.2007.08.009

13. Bonache V., Salvador M. D., Rocha V. G., Borrell A. (2011): Microstructural control of ultrafine and nanocrystalline WC-12Co-VC/ $\mathrm{Cr}_{3} \mathrm{C}_{2}$ mixture by spark plasma sintering. Ceramics International, 37, 1139-1142. doi:10.1016/j. ceramint.2010.11.026 